\title{
Comparing of Fine Needle Aspiration Cytology (FNAC) and Tru-cut biopsy for the Diagnosis of Breast Pathology
}

\author{
Bidyut Chandra Debnath ${ }^{1}$, Abanti Ghosh ${ }^{2}$, Abul Kalam Chowdhury ${ }^{3}$, Rana Jahangir ${ }^{4}$, Ferdous Alam ${ }^{5}$, \\ Aminul Islam Joardar ${ }^{6}$, Towhidul Alam ${ }^{7}$ \\ ${ }^{1}$ Assistant Professor \& Resident Surgeon, Department of Surgery, Bangabandhu Sheikh Mujib Medical University, Dhaka, \\ Bangladesh; ${ }^{2}$ Lecturer, Department of Physiology, Mugda Medical College, Dhaka, Bangladesh; ${ }^{3}$ Associate Professor, \\ Department of Surgery, Bangabandhu Sheikh Mujib Medical University, Dhaka, Bangladesh; ${ }^{4}$ Medical Officer, \\ Department of Surgery, Bangabandhu Sheikh Mujib Medical University, Dhaka, Bangladesh; ${ }^{5}$ Associate Professor, \\ Department of Surgery, Bangabandhu Sheikh Mujib Medical University, Dhaka, Bangladesh; ${ }^{6}$ Professor, \\ Department of Surgery, Bangabandhu Sheikh Mujib Medical University, Dhaka, Bangladesh; 'Chairman, \\ Department of Surgery, Bangabandhu Sheikh Mujib Medical University, Dhaka, Bangladesh
}

[Received on: 22 November 2020; Accepted on: 12 December 2020; Published: 1 January 2021]

\begin{abstract}
Background: Diagnosis of breast pathology is very important for the management of the patients. Objective: The purpose of the present study was to compare the fine needle aspiration cytology (FNAC) and trucut biopsy for the diagnosis of breast pathology. Methodology: This analytical cross-sectional study was conducted in the Department of Surgery at Bangabandhu Shiekh Mujib Medical University, Dhaka, Bangladesh from 1 April to 31 October 2020 for a period of six months. All the women who were attended at the OPD of the Department of Surgery with the different complaints of breast at any age were selected as study population. The different disease profiles were recorded in the data sheet. Result: A total number of 200 patients were recruited for this study. The mean age with standard deviation was $33.85 \pm 7.969$ years. The male and female ratio was $1: 19$. Breast pathology was found in equal in left and right side which was $100(50.0 \%)$ cases in each. The central zone was the most common area which was $90(45.0 \%)$ cases. Most of the breast pathology was firm which was $170(85.0 \%)$ cases. The comparison of FNAC and tru-cut biopsy was done. Fibroadenoma was found in $50(100.0 \%)$ cases in FNAC; but in tru-cut biopsy $10(20.0 \%)$ case was fibroadenoma; invasive ductal carcinoma was in 30(60.0\%) cases and the rest of $10(20.0 \%)$ case was Phylloides tumor. In FNAC 1 case was diagnosed as gynaecomatia which was diagnosed as intradermal papilloma in tru-cut biopsy. The difference between the FNAC and tru-cut biopsy for the detection of different pathology of breast was statistically significant $(\mathrm{p}=0.000)$. Conclusion: In conclusion there is a significant difference between FNAC and tru-cut biopsy for the detection of breast pathology. [Journal of National Institute of Neurosciences Bangladesh, January 2021;7(1): 33-37]
\end{abstract}

Keywords: : Comparison; Fine Needle Aspiration Cytology; FNAC; Trucut biopsy; Breast Pathology

Correspondence: Dr. Bidyut Chandra Debnath, Assistant Professor \& Resident Surgeon, Department of Surgery, Bangabandhu Sheikh Mujib Medical University, Dhaka, Bangladesh; Email: drbidyut2015@gmail.com; Cell no.: +8801717571582

Conflict of interest: There is no financial conflict of interest relevant to this paper to disclose.

Funding agency: This research project was not funded by any group or any institution.

Contribution to authors: Debnath BC, Rassell M, Ahmed HS contributed from the protocol preparation, data collection up to report writing. Manuscript writing was performed by Debnath BC; Ghosh A, Alam F, Chowdhury AK, Joarder AI have revised the manuscript.

How to cite this article: Debnath BC, Rassell M, Ahmed HS, Ghosh A, Alam F, Chowdhury AK, Joarder AI. Comparing of Fine Needle Aspiration Cytology (FNAC) and Tru-cut biopsy for the Diagnosis of Breast Pathology. J Natl Inst Neurosci Bangladesh, 2021;7(1): 33-37

Copyright: (C2021. Debnath et al. Published by Journal of National Institute of Neurosciences Bangladesh. This article is published under the Creative Commons CC BY-NC License (https://creativecommons.org/licenses/by-nc/4.0/). This license permits use, distribution and reproduction in any medium, provided the original work is properly cited, and is not used for commercial purposes.

\section{Introduction}

Breast cancer still represents the leading tumor among women and the incidence of the disease is rising all over the world ${ }^{1}$. The risk of developing breast cancer is related to a number of factors including the events of reproductive life and lifestyle factors that modify endogenous levels of sex hormones ${ }^{2}$. Diet has been also found to play an important role in the etiology of breast 
cancer. There is increasing awareness with associated anxiety and stress among women, who perceive every symptom in breast as cancer, compelling them to seek medical advice ${ }^{3}$. It is sometimes difficult to determine whether a suspicious lump is benign or malignant simply from clinical assessment ${ }^{4}$.

Due to its increasing incidence, morbidity and mortality breast cancer is the commonest malignant tumour responsible for $18.4 \%$ of all female cancers worldwide 5 . As it is the leading cause of death from cancer in women, the major concern of the surgeon and the responsibility of the surgical pathologist lies in the ability to differentiate a benign from a malignant lesion. Fine-needle aspiration cytology (FNAC), core needle biopsy (CNB) and vacuum assisted breast biopsy (VABB) represent the current methods of choice for pathological diagnosis, both with their specific advantages and limitations ${ }^{6}$.

Self-breast examination along with triple test which includes clinical examination, mammogram and Fine Needle Aspiration Cytology (FNAC) has reduced the false negative rate to less than $1.0 \%$ cases $^{5}$. The diagnostic accuracy of FNAC increases to $99.0 \%$ when it is combined with clinical and radiological examination and accuracy further increases to $100.0 \%$ when it is combined with cell block preparation?

In case of detected breast nodules, FNAC is a well-established method for the diagnosis of breast lesions in many countries ${ }^{8}$. It has the advantages of being highly accurate in experienced hands, cost effective, and useful for small lesions not eligible for CNB. Its limitations are represented by the lack of experienced cytologists in many institutions, the inability to reliably distinguish invasive from in situ carcinoma and the difficulty in precisely evaluating cytological and morphologic features in breast aspirates with the histological classification system used as the "gold-standard", particularly in benign lesions.

\section{Methodology}

This analytical cross-sectional study was conducted in the Department of Surgery at Banghabandhu Sheikh Mujib Medical University, Dhaka, Bangladesh from 1 April to 31 October 2020 for a period of six months. All the women who were attended at the OPD of the department of Surgery with the different complaints of breast at any age were selected as study population. The women with different morbidities were seeking medication in the only medical university in Bangladesh. This was representing the whole country patients' burden. The age, pattern of disease were recorded in a predesigned data sheet. Fine needle aspirations were done by pathologists in the Department of Pathology at Banghabandhu Sheikh Mujib Medical University, Dhaka, Bangladesh by using between $10 \mathrm{ml}$ to $20 \mathrm{ml}$ syringe with $23 \mathrm{G}$ needle. Smears were stained with Haematoxylin and Eosin $(\mathrm{H} \& \mathrm{E})$, Papanicolaou and Giemsa stains. Tru-Cut biopsy (TCB) was performed using a Tru-Cut gun with an 18-gauge needle. After manual localization and immobilization of the lesion under complete aseptic technique, a $2 \%$ lignocaine-infiltrating anesthetic was administered and a skin incision was performed. A biopsy specimen was obtained by means of 4 successive insertions with different angulations of the needle into the lesion's core. After immediate immersion of the specimen in a fixative, its quantity and quality were judged and it was sent to the histopathology department. All breast masses were clinically palpable. The research protocol was approved by the Local Ethics Committee. Statistical analysis was performed by Windows based software named as Statistical Package for Social Science (SPSS), versions 22.0 (IBM SPSS Statistics for Windows, Version 22.0. Armonk, NY: IBM Corp.). Continuous data that were normally distributed were summarized in terms of the mean, standard deviation. Categorical or discrete data were summarized in terms of frequency counts and percentages. For end points analysis, Chi-square test was performed which was corrected by Fisher's exact test was used for categorical variables. A two-sided $\mathrm{P}$ value of less than 0.05 was considered to indicate statistical significance.

\section{Results}

A total number of 20 patients were recruited for this study after fulfilling the inclusion and exclusion criteria. Majority of the patients were in the age group of less than 40 years which was $16(80.0 \%)$ cases and the rest were in the age group of more than 40 years of age. The mean age with standard deviation was $33.85 \pm 7.969$ years with the range of 18 to 45 years (Table 1).

Table 1: Age Distribution among the Study Population $(\mathrm{n}=200)$

\begin{tabular}{lcc}
\hline Age Group & Frequency & Percent \\
\hline Less Than 40 Years & 160 & 80.0 \\
More Than 40 Years & 40 & 20.0 \\
Total & $\mathbf{2 0 0}$ & $\mathbf{1 0 0 . 0}$ \\
Mean \pm SD (Years) & $\mathbf{3 3 . 8 5} \pm \mathbf{7 . 9 6 9 ( 1 8 - 4 5 )}$ \\
\hline
\end{tabular}

In this study most of the study population were female which $190(95.0 \%)$ cases was and the rest $10(5.0 \%)$ case 
was male. The male and female ratio was 1:19 (Figure I).

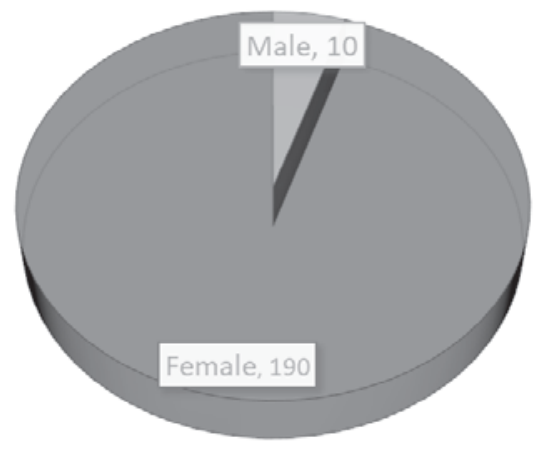

Figure I: Gender Distribution of Study Population $(n=200)$

Breast pathology was found in equal in left and right side which was $100(50.0 \%)$ cases in each. The central zone was the most common area which was $90(45.0 \%)$ cases followed by upper outer quadrant which was $70(35.0 \%)$ cases. Most of the breast pathology was firm which was $170(85.0 \%)$ cases followed by tender soft which was $20(10.0 \%)$ cases (Table 2).

The comparison of FNAC and tru-cut biopsy was done. Breast abscess was found in 5(100.0\%) cases in both tru-cut biopsy and FNAC. Fibroadenoma was found in $5(100.0 \%)$ cases in FNAC; but in tru-cut biopsy $1(20.0 \%)$ case was fibroadenoma; invasive ductal carcinoma was in $3(60.0 \%)$ cases and the rest of $1(20.0 \%)$ case was Phylloides tumor. In FNAC 1 case was diagnosed as gynaecomatia which was diagnosed as intradermal papilloma in tru-cut biopsy. Invasive ductal carcinoma was found in $3(100.0 \%)$ cases which was found similar in tru-cut- biopsy. Traumatic Fat Necrosis was found in similar in FNAC and tru-cut biopsy. The difference between the FNAC and tru-cut
Table 2: Clinical Variables of Study Population $(n=20)$

\begin{tabular}{lcc}
\hline Variables & Frequency & Percent \\
\hline Side & 100 & \\
Left & 100 & 50.0 \\
Right & & 50.0 \\
Quadrant & 90 & \\
Central & 10 & 45.0 \\
Diffuse & 10 & 5.0 \\
LIQ & 10 & 5.0 \\
LOQ & 10 & 5.0 \\
UIQ & 70 & 5.0 \\
UOQ & & 35.0 \\
Consistency & 170 & \\
Firm & 10 & 85.0 \\
Hard & 20 & 5.0 \\
Tender Soft & & 10.0 \\
\hline
\end{tabular}

LIQ=Left inner quadrant; $L O Q=$ Left outer quadrant; $\mathrm{UIQ}=$ upper inner quadrant; $\mathrm{UOQ}=$ Upper outer quadrant

biopsy for the detection of different pathology of breast was statistically significant $(\mathrm{p}=0.000)$ (Table 3 ).

\section{Discussion}

To ensure an accurate diagnosis, the combination of a good clinical eye, high-quality imaging, and appropriate pathological techniques is important? ${ }^{7}$. For several years, fine needle aspiration cytology (FNAC) was the most practiced method for the pathological diagnosis of breast masses. FNAC became popular because of its accuracy, cost effectiveness, and ease of use ${ }^{8-12}$. A total number of 200 patients were recruited for this study after fulfilling the inclusion and exclusion criteria. Majority of the patients were in the age group of less than 40 years which was $160(80.0 \%)$ cases and the rest were in the age group of more than 40 years of age. The mean age with standard deviation was $33.85 \pm 7.969$ years with the range of 18 to 45 years

Table 3: Comparison of Tru-cut Biopsy and FNAC among the study Population

\begin{tabular}{|c|c|c|c|c|c|c|c|}
\hline \multirow[t]{2}{*}{$\overline{\text { FNAC }}$} & \multicolumn{6}{|c|}{ Tru-cut Biopsy } & \multirow[t]{2}{*}{ Total } \\
\hline & Abscess & Fibroadenoma & IDC & $\begin{array}{c}\text { Intradermal } \\
\text { Papilloma }\end{array}$ & $\begin{array}{l}\text { Phylloides } \\
\text { Tumor }\end{array}$ & $\begin{array}{l}\text { Phylloides } \\
\text { Tumor }\end{array}$ & \\
\hline Abscess & $50(100.0 \%)$ & $0(0.0 \%)$ & $0(0.0 \%)$ & $0(0.0 \%)$ & $0(0.0 \%)$ & $0(0.0 \%)$ & $50(100.0 \%)$ \\
\hline Fibroadenoma & $0(0.0 \%)$ & $10(20.0 \%)$ & $30(60.0 \%)$ & $0(0.0 \%)$ & $10(20.0 \%)$ & $10(20.0 \%)$ & $50(100.0 \%)$ \\
\hline Gynaecomatia & $0(0.0 \%)$ & $0(0.0 \%)$ & $0(0.0 \%)$ & $10(100.0 \%)$ & $0(0.0 \%)$ & $0(0.0 \%)$ & $10(100.0 \%)$ \\
\hline IDC & $0(0.0 \%)$ & $0(0.0 \%)$ & $30(100.0 \%)$ & $0(0.0 \%)$ & $0(0.0 \%)$ & $0(0.0 \%)$ & $30(100.0 \%)$ \\
\hline Intradermal Papilloma & $0(0.0 \%)$ & $0(0.0 \%)$ & $0(0.0 \%)$ & $20(100.0 \%)$ & $0(0.0 \%)$ & $0(0.0 \%)$ & $20(100.0 \%)$ \\
\hline Suspicious & $0(0.0 \%)$ & $0(0.0 \%)$ & $30(100.0 \%)$ & $0(0.0 \%)$ & $0(0.0 \%)$ & $0(0.0 \%)$ & $30(100.0 \%)$ \\
\hline Traumatic Fat Necrosis & $0(0.0 \%)$ & $0(0.0 \%)$ & $0(0.0 \%)$ & $0(0.0 \%)$ & $0(0.0 \%)$ & $0(0.0 \%)$ & $10(100.0 \%)$ \\
\hline Total & $50(25.0 \%)$ & $10(5.0 \%)$ & $90(45.0 \%)$ & $30(15.0 \%)$ & $10(5.0 \%)$ & $10(5.0 \%)$ & $200(100.0 \%)$ \\
\hline
\end{tabular}

Chi-square test was performed to see the level of significance. 
Breast pathology was found in equal in left and right side which was $100(50.0 \%)$ cases in each. The central zone was the most common area which was $9(45.0 \%)$ cases followed by upper outer quadrant which was $7(35.0 \%)$ cases. Most of the breast pathology was firm which was $170(85.0 \%)$ cases followed by tender soft which was 20(10.0\%) cases. The advent of core needle or Tru-Cut biopsy (TCB) in the new millennium has resulted in many surgeons switching to TCB since it provides a sufficient amount of tissue for pathologists to make an accurate histological diagnosis. It is now the initial investigation method of choice for pre-operative diagnosis of breast lesions. Some studies have suggested that TCB is superior to FNAC to some extent. The sensitivity of FNAC increases when TCB biopsy is also performed ${ }^{13}$. TCB can provide all the necessary details to guide both the surgeon and the oncologist in designing an appropriate therapeutic strategy for the management of patients with breast masses $^{14}$.

Although open surgical biopsy is the 'gold standard' for diagnosis of palpable breast lesions, in recent years two types of minimally invasive breast biopsy techniques, core needle biopsy (CNB) and fine needle aspiration cytology (FNAC), have become established for the diagnostic evaluation of palpable breast lesions ${ }^{15}$. A triple test consisting of clinical examination, mammography and FNAC is considered the gold standard in making a definitive assessment of breast lumps ${ }^{11}$.

The comparison of FNAC and tru-cut biopsy was done. Breast abscess was found in 50(100.0\%) cases in both tru-cut biopsy and FNAC. Fibroadenoma was found in $50(100.0 \%)$ cases in FNAC; but in tru-cut biopsy $10(20.0 \%)$ case was fibroadenoma; invasive ductal carcinoma was in $30(60.0 \%)$ cases and the rest of $1(20.0 \%)$ case was Phylloides Tumor. In FNAC 1 case was diagnosed as gynaecomatia which was diagnosed as intradermal papilloma in tru-cut biopsy. Invasive ductal carcinoma was found in 3(100.0\%) cases which was found similar in tru-cut- biopsy. Traumatic Fat Necrosis was found in similar in FNAC and tru-cut biopsy. The difference between the FNAC and tru-cut biopsy for the detection of different pathology of breast was statistically significant $(p=0.000)$. In resource poor settings like ours, FNAC comes readily useful for its obvious advantages. It is a cheap, fast, and reliable diagnostic method. It also reduces the frequency of open biopsies. Some of the setback of FNAC include pain and haematoma formation. It has also been found to have the potential to mask radiological assessment when done prior to mamography ${ }^{13}$. It is also possible that the smears may be acellular (no cells are harvested) making cytological analysis impossible. These are described as inadequate aspirates and rates vary markedly, being particularly operator dependent and cases have to be converted to $\mathrm{CNB}$ which is able to solve the problem ${ }^{15}$.

\section{Conclusion}

In conclusion there is a significant difference between FNAC and tru-cut biopsy for the detection of breast pathology. The diagnosis of benign changes or a normal breast by tru-cut biopsy would reassure the patient about the absence of malignancy and these cases can be followed-up in outpatient clinics. Patients in the current study who have benign breast lesions diagnosed accurately by tru-cut has saved a lot of expenses and did not undergo unnecessary surgical procedures that would have been an additional burden on the healthcare system. The use of tru-cut also lessens the propensity of complicated surgical procedures and minimizes patient stress. In patients with malignant lesions, in addition to having diagnostic significance, TCB also provides adequate tissue for the evaluation of molecular markers which have extreme therapeutic value.

\section{References}

1. Ibikunle DE, Omotayo JA, Ariyibi OO. Fine needle aspiration cytology of breast lumps with histopathologic correlation in Owo, Ondo State, Nigeria: a five-year review. Ghana Medical Journal. 2017;51(1):1-5

2. Yong WS, Chia KH, Poh WT, Wong CY. A comparison of trucut biopsy with fine needle aspiration cytology in the diagnosis of breast cancer. Singapore Med J. 1999;40(9):587-589

3. Rahman MZ, Islam S. Fine needle aspiration cytology of palpable breast lump: A study of 1778 cases. Surgery S. 2013;12:2161-1076.

4. Obaseki DE, Olu-Edo AN, Ogunbiyi JO. Diagnostic accuracy of fine needle aspiration cytology of palpable breast masses in Benin City, Nigeria. West Afr J Med. 2010;29(4):259-262

5. Kaufman Z, Shpitz B, Shapiro M, Rona R, Lew S, Dinbar A. Triple approach in the diagnosis of dominant breast masses: combined physical examination, mammography, and fine-needle aspiration. Journal of surgical oncology. 1994 Aug;56(4):254-7

6. Ukah $\mathrm{CO}$, Oluwasola OA. The clinical effectiveness of fine needle aspiration biopsy in patients with palpable breast lesions seen at the University College Hospital, Ibadan, Nigeria: A 10-year retrospective study. Journal of Cytology/Indian Academy of Cytologists. 2011 Jul;28(3):111

7. Daramola AO, Odubanjo MO, Obiajulu FJ, Ikeri NZ, Banjo AA. Correlation between fine-needle aspiration cytology and histology for palpable breast masses in a Nigerian tertiary health institution. International journal of breast cancer. 2015 Jan 1;2015.

8. Rikabi A, Hussain S. Diagnostic usefulness of tru-cut biopsy in the diagnosis of breast lesions. Oman medical journal. 2013;28(2):125 
9. Verenhitach BD, Elias S, Patrocínio AC, Nazário AC, Waizberg A. Evaluation of the clinical efficacy of minimally invasive procedures for breast cancer screening at a teaching hospital. J Clin Pathol 2011. Oct;64(10):858-861

10. Mendoza P, Lacambra M, Tan PH, Tse GM. Fine needle aspiration cytology of the breast: the non-malignant categories. Patholog Res Int 2011; 2011:547580

11. Berner A, Sauer T. Fine-needle aspiration cytology of the breast. Ultrastruct Pathol 2011. Aug;35(4):162-167

12. Kurita T, Tsuchiya SI, Watarai Y, Yamamoto Y, Harada O, Yanagihara $\mathrm{K}$, et al. Roles of fine-needle aspiration and core needle biopsy in the diagnosis of breast cancer. Breast Cancer 2012. Jan;19(1):23-29
13. Hashemzadeh SH, Kumar PV, Malekpour N, Hashemi Z, Fattahi F, Malekpour F. Diagnostic accuracy of fine needle aspiration cytology: comparison of results in Tabriz Imam Khomeini Hospital and Shiraz University of Medical Sciences. Iranian J Cancer Prev 2009;2(3):133-136

14. Bdour M, Hourani S, Mefleh W, Shabatat A, Karadsheh S, Nawaiseh $\mathrm{O}$, et al. Comparison between fine needle aspiration cytology and tru-cut biopsy in the diagnosis of breast cancer. J Surg Pak 2008;13(1):19-21

15. Lacambra MD, Lam CC, Mendoza P, Chan SK, Yu AM, Tsang JY, et al. Biopsy sampling of breast lesions: comparison of core needle- and vacuum-assisted breast biopsies. Breast Cancer Res Treat 2012;132(3):917-923 